\title{
REVERSE MODELING OF CULTURAL HERITAGE: PIPELINE AND BOTTLENECKS
}

\author{
F. Camagni ${ }^{1}$, S. Colaceci $^{2}$, M. Russo ${ }^{3}$ \\ Department of History, Representation and Restoration of Architecture, Sapienza University of Rome \\ 1flavia.camagni@uniroma1.it, 25ara.colaceci@uniroma1.it, ${ }^{3}$ m.russo@uniroma1.it
}

Commission II

KEY WORDS: Reverse modelling, Massive survey, Cultural Heritage, Multi-scale 3D, NURBS, Mathematical models

\begin{abstract}
:
The present work is suggested as a contribution to the debate on Reverse Modeling (RM) topic in the Cultural Heritage field. It wants to test the methodology, the limits and the bottlenecks of the RM pipeline in the architectural field, with particular attention to the geometric shapes reading and interpretation. The mathematical reconstruction of architectural models represents an overlaid result of anthropic and natural transformations framed inside a complex process of shape simplification and surface generation. This pipeline must be supported by a careful Heritage reading by means of architecture rules, both preserving the actual shape and the original intent of the building designer. The integration of these last two aspects make the process of RM applied to $\mathrm{CH}$ extremely complex. It involves a cognitive activity aimed at choosing on the one hand the best $3 \mathrm{D}$ survey technique to obtain reliable $3 \mathrm{D}$ data, on the other hand reaching a suitable architectural knowledge for achieving a plausible modeling result. The research presented describes a RM process applied to an ecclesiastical architecture, highlighting some key passages: an integrated survey approach to extract geometrical information, data analysis and generation of a mathematical 3D model, reliable from both a formal and cultural point of view.
\end{abstract}

\section{INTRODUCTION}

The present work is proposed as a contribution to the debate on Reverse Modeling of architecture in the Cultural Heritage field ${ }^{1}$. Integrated multi-scale 3D acquisition represents a well-known activity in $\mathrm{CH}$, experimented since the early 2000s. After almost two decades from these first pioneering researches, the methodology of 3D acquisition and integration between active and passive sensors is consolidated, collecting massive amounts of 3D data ever more bound both to technological innovations and data management advances, which sometimes can affect the pipeline itself. This process can foresee different passages, in relation with the application field: in the engineering sector, for example, it is often named "reverse engineering", while in the field of design or architecture it is called "reverse modeling", mainly indicating the distinction between the purpose of product engineering rather than 3D modeling of real artefact.

In the Industrial Design field the mathematical 3D reconstruction of real object has been consolidated more than ten years ago, passing through several steps characterized by stringent reconstructive tolerances on the surveyed shape, which do not refer to construction rules of the real object.

Besides, the mathematical reconstruction of architecture or archaeological artefacts is quite different, because the final shape of the building is the overlaid result of various factors such as foundation, anthropic transformations, time and climatic events, which must be combined with a complex process of shape simplification. This should be guided by a careful Heritage reading by means of architecture rules, both preserving the actual shape and the original intent of the building designer. These last two aspects make the process of Reverse Modeling applied to Cultural Heritage extremely complex, since it involves a cognitive activity that combines on the one hand the knowledge and management of the relevant techniques to obtain a reliable 3D data, on the other hand an architectural understanding necessary to achieve a plausible result. The intermediate and final output of a RM pipeline can be summarized as follows: highdensity point clouds, reality-based polygonal models and mathematical models. Starting from the point cloud, the polygonal model generation can present some bottlenecks in

\footnotetext{
${ }^{1}$ The research has seen the survey activity of all the authors, the modeling step was carried out by F.C. and S.C. The paragraphs
}

cleaning mesh, topological correction, closing holes up to surface optimization and remeshing. In all these steps the preservation of initial geometrical data is framed inside precise and predefined tolerances. Even the reconstruction of 3D mathematical models presents many variables, in which the starting datum is not referred to the survey activity but to a simplified geometry, resulted by a real data interpretation and transformation.

The research presented aims to describe a complete process of Reverse Modeling applied to an ecclesiastical architecture, highlighting the main steps from a methodological point of view, from the integrated survey of geometric data to the extraction of data useful for reconstruction, from the geometric analysis of sections to the generation of a mathematical 3D model, reliable from both a formal and cultural point of view.

So, the purpose of the article is to highlight the process bottlenecks, suggesting for each a possible solution, testing the limits and potentials of a massive survey used to create an ideal $\mathrm{CH}$ 3D model, which presents stylistic features of classical architecture with different levels of detail.

\section{RELATED WORKS}

In the literature, the first studies devoted to 3D acquisition and modeling, stressing the various steps (data acquisition, preprocessing, segmentation and surface adaptation, creation of CAD models), refers to the end of the last century (Varady et al., 1997; Motavalli, 1998). Besides, a research aimed at a categorization of modeling techniques, the modeling phases, the classification of the main strategies for the generation of 3D models, identifying the advantages and disadvantages of each is proposed in recent studies (Buonamici et al., 2018).

In the Reverse Modeling field numerous contributions are focused on the description of the whole process, but few of these are devoted to highlight data interpretation for mathematical modeling in different application areas (engineering, architectural, mechanical, naval, design, medical).

The literature related to Reverse Modeling pipeline in Cultural Heritage shows that this technological and cognitive process is often stopped at the first passage, extracting data useful for the definition of geometric projections (plants, elevations, sections).

1-4-6 were written by M.R., the paragraphs 2-5.1 were written by S.C., the paragraphs 3-5.2 were written by F.C. 
In fact, many examples of "reality-based" and "reconstructive" 3D models in $\mathrm{CH}$ are devoted to reach a geometric knowledge of the artefact, thus making unnecessary to realize an important effort from the cultural, intellectual and human/time point of view, reconstructing numerical or mathematical $3 \mathrm{D}$ models. The former, in its complexity, represent the extension of the collected 3D data, from which the polygonal surface is generated, creating high communicative virtual product.

In the field of $\mathrm{CH}$, the studies of Levoy (Levoy et al., 2000) concern the geometric complexity of the monument. Bernardini e Rushmeier (Bernardini and Rushmeier, 2002) were the first to define a $3 \mathrm{~d}$ modelling acquisition pipeline.

According to Remondino and El-Hakim "Three-dimensional (3D) modelling of an object can be seen as the complete process that starts from data acquisition and ends with a $3 \mathrm{D}$ virtual model visually interactive on a computer. Often $3 \mathrm{D}$ modelling is meant only as the process of converting a measured point cloud into a triangulated network ("mesh") or textured surface, while it should describe a more complete and general process of object reconstruction" (Remondino and El-Hakim, 2006). Numerous authors have already clarified the difference between numerical and mathematical model in the architectural field and highlighted the potentialities and the critical aspects of both.

The researches on archaeological sites showed the 3D model capacity, used both as representation and interface object for information system associated with heterogeneous information, such as texts, photographs, drawings, films (Gaiani et al., 2007). The issues related to the model as architectural knowledge system, i.e. composed of precise elements and vocabularies related to that field, is offered by the authors on the research on Pompeii site (Benedetti et al., 2010; Gaiani et al., 2011; Gaiani, 2012), in which the digital $3 \mathrm{~d}$ model becomes "an aggregative nucleus of the systems information on the scale of the object (PLM - Product Lifecycle Management), on the scale of the territory (GIS - Geographic Information System), passing through the architectural one (BIM - Building Information Model)" (Gaiani et al., 2011).

The semantic segmentation of the numerical model aimed at analysing the formal composition of the architectural structure is an unavoidable aspect for the knowledge of the architectural heritage. It is propaedeutic for the subsequent identification of the geometric components, intended as an existential proof of the form (Fallavolita et al., 2015). The hierarchical model decomposition into macro-categories, up to the single architectural component, is aimed at understanding the parts and the way in which they are connected. Semantic classification is functional not only to knowledge but also to modeling procedures (Apollonio et al., 2010). Furthermore different levels of procedural reconstruction characterized by a progressive increase in uncertainty are defined, with the aim of obtaining various dynamic digital graphic models (two-dimensional and threedimensional).

The use of three-dimensional mathematical models aimed at future actions on historic architecture (restoration interventions, structural evaluations, construction problems, design simulations) is also analysed, highlighting modeling techniques in relation with its graphic restitution, the level of detail and on the object discretization (Brusaporci, 2012; Brusaporci et al., 2012). Other researches applied RM process up to the theoretical virtual reconstruction of non-more existing architecture (Guidi and Russo, 2011) or ancient artefacts in its original state (Guidi at al., 2014), aimed at raising the architecture knowledge through $3 \mathrm{D}$ immersive visualization and $3 \mathrm{D}$ printing. In this process the reading and geometric interpretation of the components becomes central and substantial in the transition from the numerical model to the mathematical one (Clini et al., 2017).

\section{THE CASE STUDY}

The case study presented in this research is the church's facade of Maria SS. Assunta in Cielo, located in Cantalupo in Sabina (RI). The church is located on the main square of the village, next to the Camuccini palace.

The actual church was built in 1703 over an old one, but the façade remained unfinished until the end of the XVIII century. The long construction do not allow a certain attribution, however the literature (Di Carlo, 1989) states that the church project is due to the architect Francesco Rosa, instead the drawing and the supervision are attributed to the architect Carlo Fontana.

In 1791 the architect Giacomo Paticchi (or Baticchi) was called for the construction of the façade. It is not clear whether he carried on the construction activity following Carlo Fontana's drawings or used a new project. The façade was conceived with a double order of composite pilasters and Tuscan pilasters in the central portion, two side parts sloped respect to the central façade, with a global dimension of about twenty meters in height and eighteen meters in width. The cognitive survey on this building, which have foreseen documental and iconographical (Fig. 1) research, also arises within a process of knowledge of the cultural heritage affected by the 2016 earthquake. The present study concerned only the façade of the church examined, because the interiors were not accessible due to the disruption caused by the recent earthquakes (Fig. 2).

\section{DATA ACQUISITION AND PRE-PROCESSING}

In the indirect survey planning, based on active and passive techniques, two different instruments has been chosen in relation with the scale acquisition and analysis: laser scanner Focus 3D X120 (Faro) for the range survey of the entire façade and digital camera D800 (Nikon) to support the photogrammetric survey of the architectural detail relating to the composite capital.

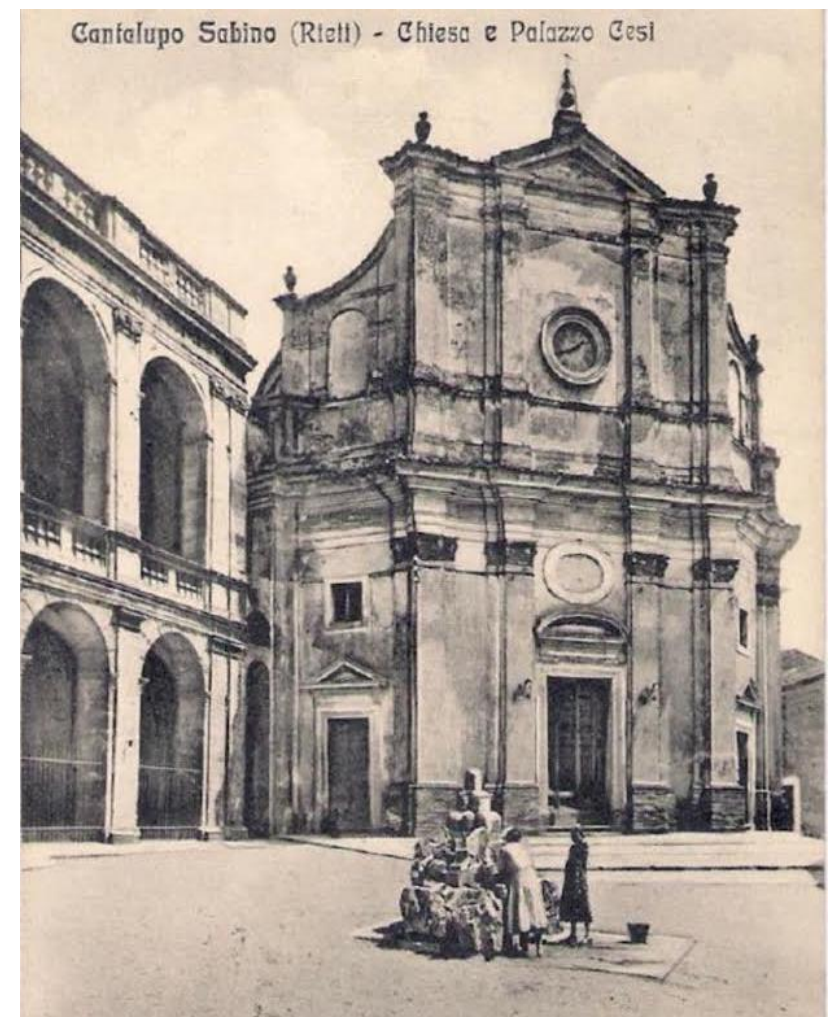

Figure 1. Historical photo of the church's facade of Maria SS. Assunta in Cielo, located in Cantalupo in Sabina (RI). 
The survey conditions, limited by the presence of a dockyard in front of the main entrance of the church, and the geometric characteristics of the façade, consisting in three different façades orientation, required four scans from 3D laser scanners (Fig. 3). The first scan position was located in the square centre, using a horizontal scan angle of 120 degrees, at distance of 15 meters. This position, not suitable for the left side acquisition of the façade, was obliged for the presence of Palazzo Camuccini, its construction site and parked cars. The working distance was considered to minimize shadows effects on the façade 3D acquisition, obtaining a final GSD of $0,9 \mathrm{~cm}$ related to the bottom façade area, with an average instrumental error of $0,09 \mathrm{~cm}$. Three scans were than performed closer to the façade, with a horizontal scan angle of 70 degrees and a GSD of $0,3 \mathrm{~cm}$, with an average instrumental error of $0,03 \mathrm{~cm}$, covering the different sides of the façade. The second scan was also devoted to acquire the lower part of the façade, covered by the dockyard presence.

The point clouds were aligned and merged in JRC Reconstructor (Gexcel) software. The final dense cloud, composed of 9500000 points, presented many lacks due to shadowing effect caused by the dockyard and the architectural elements such as the trabeation. Within the same software it was possible to obtain vertical sections, horizontal sections and a polygonal model. The façade morphology and the presence of different architectural orders required the creation of more sections, in order to obtain useful complete data for each plane of the façade. This geometrical data were indispensable for the identification of significant points, basic for the 2D CAD model construction.

For the capitals a second acquisition campaign was planned, using digital camera. During the survey, about 14 photographs were acquired for each capital, with manual exposure set-up, focal length of $70 \mathrm{~mm}$, exposure time of $1 / 400$, ISO 160 . The photos have dimensions 7360 x 4912 pixels, resolution $300 \mathrm{dpi}$, bit depth 24. The final GSD is of $0,065 \mathrm{~cm}$. This acquisition step was necessary to deepen the information of some architectural details. The images orientation and point cloud reconstruction were based on photogrammetric and structure from motion approach inside Photoscan (Agisoft) software.

All the capitals have been elaborated until obtaining a dense cloud. The comparison between the dense cloud did not produce significant differences, so a capital was used to obtain the necessary information and produce the mesh. In the image-based modeling pipeline a dense cloud of 6 million points has been created and a final polygonal model of 15 million faces has been defined.

\section{MATHEMATICAL MODEL RECONSTRUCTION}

\subsection{The global façade}

The generation of a mathematical 3D model was motivated by two main reasons, a theoretical and pragmatic one. The first concerns the consideration that a mathematical model is not defined by a set of triangulated meshes but by the combination of NURBS surfaces constituting known volumes, namely architectural forms as they were conceived by the designer architect. The model, in this way, can provide information on the geometric nature of the acquired object. The second concerns the possibility of carrying out simulations and consequent evaluations concerning the compositional and perceptive aspects of the artefact.

An ideal model aimed at recognizing the initial project more than the imperfect dimensions of the "artefact", considered as a product of man's manual activity, was than created. The modeling process was carried on in Rhinoceros (McNeel) software, establishing three orthogonal axes as a model reference in a

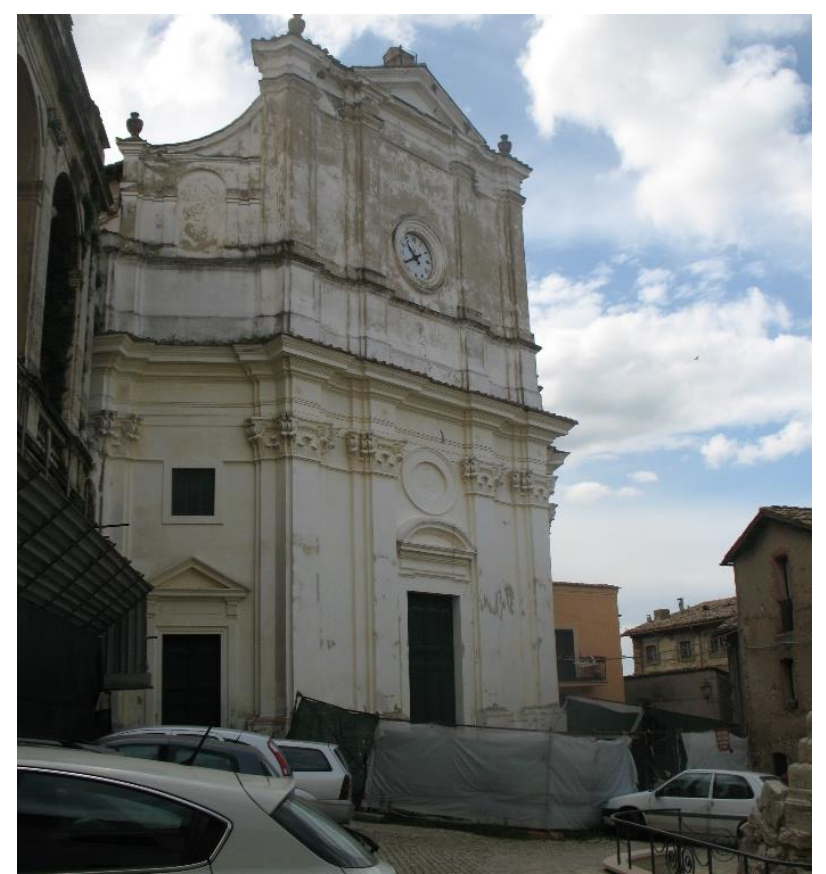

Figure 2. Current photo of the church's facade of Maria SS. Assunta in Cielo, located in Cantalupo in Sabina (RI).

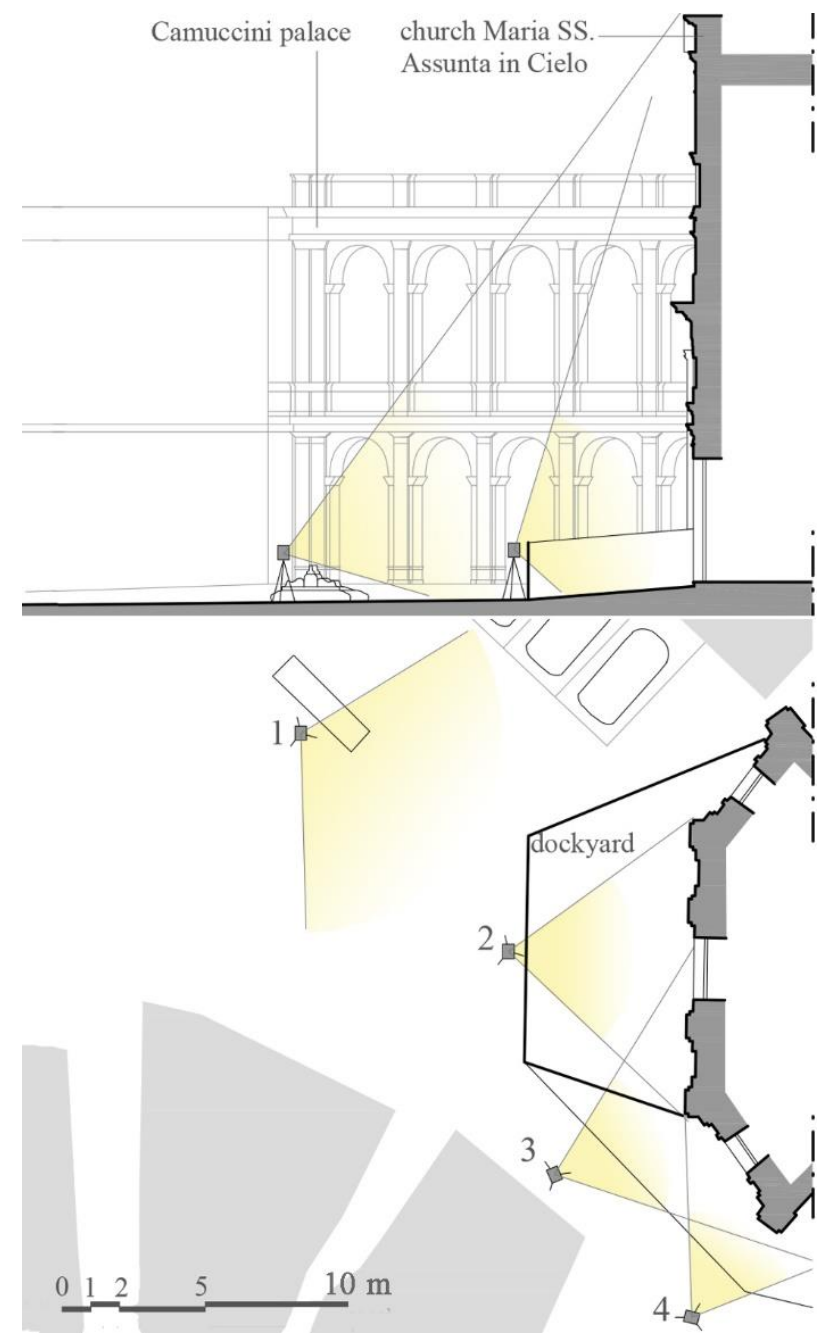

Figure 3. Position of the laser scanner in the square and in the street near the church. 


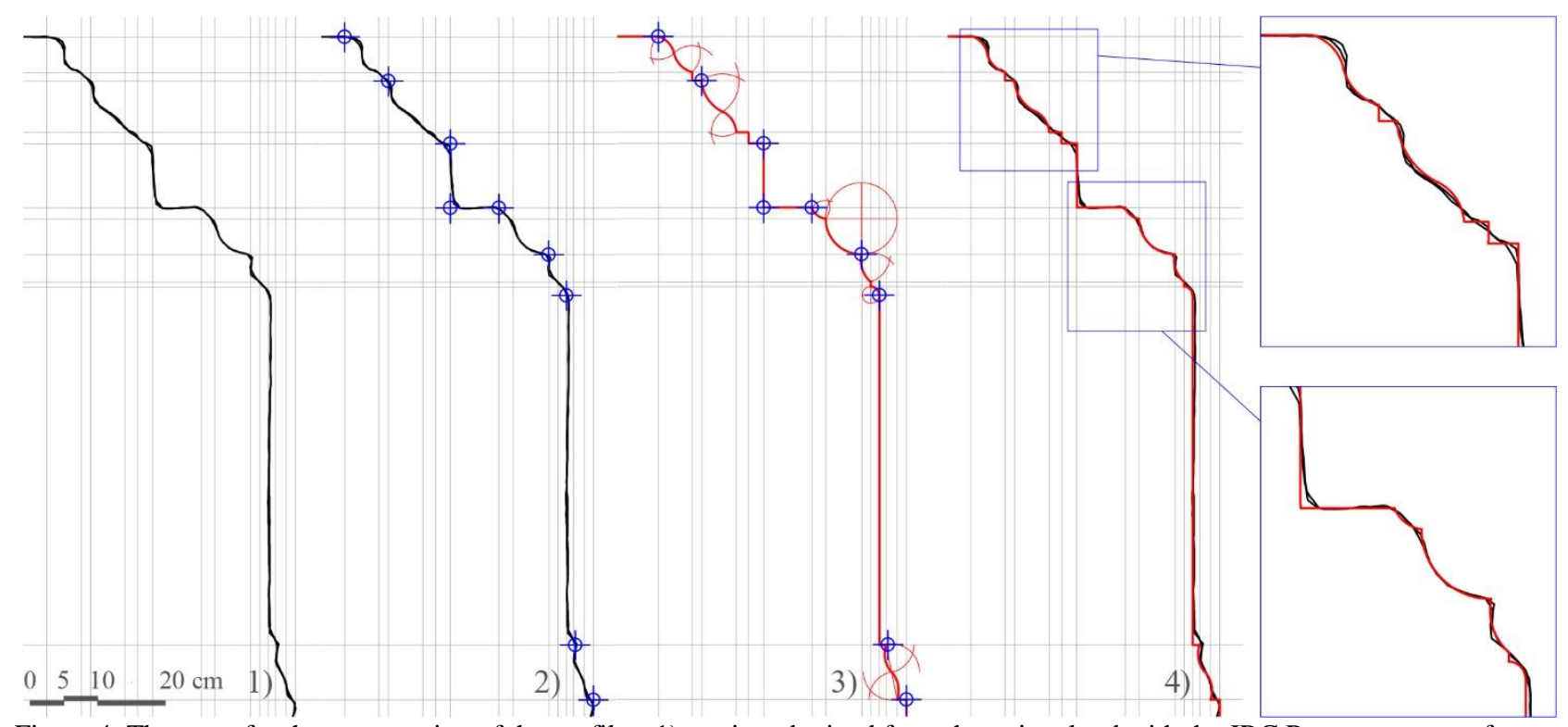

Figure 4. The steps for the construction of the profiles: 1) section obtained from the point cloud with the JRC Reconstructor software; 2) identification of significant points; 3) interpretation and geometric construction of mouldings; 4) comparison between the section and the determined profile

starting step, accepting the hypothesis of factory symmetry according to the vertical axis. Considering the geometrical characteristics of the object, a layer classification of the elements was necessary to organize the modeling phases. For this, horizontal façade sections extracted in JRC Reconstructor software, were organized in different layers. Subsequently, the elements were modelled according to the hierarchy of the architectural order: first order, second order, terminal tympanum, portals, secondary elements (oval, clock).

Regarding mouldings profiles, an interpretative phase of the acquired data was carried on for the portals, the frames, the bases, the capitals, the trabeation and the terminal tympanum. In this step sections extracted from the point cloud in JRC Reconstructor have been essential for defining geometrical shape, even if they did not contain enough data to complete a formal and geometrical interpretation. This bottleneck was mainly due to the 3D survey lacks which made the point cloud insufficient for the modeling purposes, integrating with interpolation and interpretation operation.

The construction of the geometric model, considered the focus of the pipeline, was based on the selection of significant points extrapolated from the massive survey, confirming again that the survey process often obliges to a second phase of careful observation and interpretation of the point cloud, in order to translate it in a graphic restitution. For this reason, interpretative choices have been adopted for model generation, deleting traces concerning the overtime conservation state of the artwork, omitting the differences between the ideal project and the building imperfection due to manual man activity.

The digital model has been achieved thanks to the integration between $3 \mathrm{D}$ acquired data and the interpretative geometric shape. The profiles of the mouldings were built by recognizing the type. This was possible through the identification of significant points in the indistinct set of sections, the photographic image and the awareness of the geometric construction underlying them codified in the treatises. The steps for the profile construction are the following (Fig. 4): section extraction from the point cloud; recognition of the significant points as a metric datum for geometric construction; geometric construction of the single mouldings following architecture rules; comparison between the section and the determined profile verifying the compliance with the predefined reconstruction tolerances.

The geometry of the profiles can be described mathematically through: circumference arcs, polycentric curves, right angles or determined angles.

The 3D model is mainly defined by translation surfaces in which the direction line is made up of horizontal sections (Fig. 5), while the generating line consists of vertical sections including mouldings. The modeling of the moulding, in a similar manner, is carried on using translation surfaces in which the direction line is constituted by the progression of the elevation while the generating line is constituted by the section.

In the mathematical modeling step a reconstruction tolerance of less than $5 \mathrm{~cm}$ from acquired data was chosen, in order to preserve the correct description of the whole architectural building. Besides, other modeling choices have been adopted along the RM pipeline. Firstly the church façade presents an outof-plumb condition, which was not considered in the modeling process because it does not affect the interpretation of the formal and compositional characteristics of architecture. In addition, some façade areas like the base one, characterized by simple architectural elements, were simplified, in accordance with the metric tolerance which preserves the architectural features.

A different modeling approach was followed for the terminal tympanum reconstruction. The actual tympanum presents a 12 $\mathrm{cm}$ asymmetry respect to the symmetrical façade axe, clearly out of reconstruction tolerances. For this reason it was decided not to simplify the moulded tympanum in the modeling step, preserving its asymmetry which characterize its shape and possible design interpretation. This reported example shows that the reconstruction of a mathematical model is not simply a mechanistic process, but a process subject to several choices aimed at simplifying the surveyed data, preserving in the meanwhile its peculiarities.

\subsection{The capital}

The mathematical modeling of the composite capital was possible thanks to the data integration between 3D laser scanners data and point cloud derived from SfM process. This condition was due firstly because data provided by the 3D laser scanner 


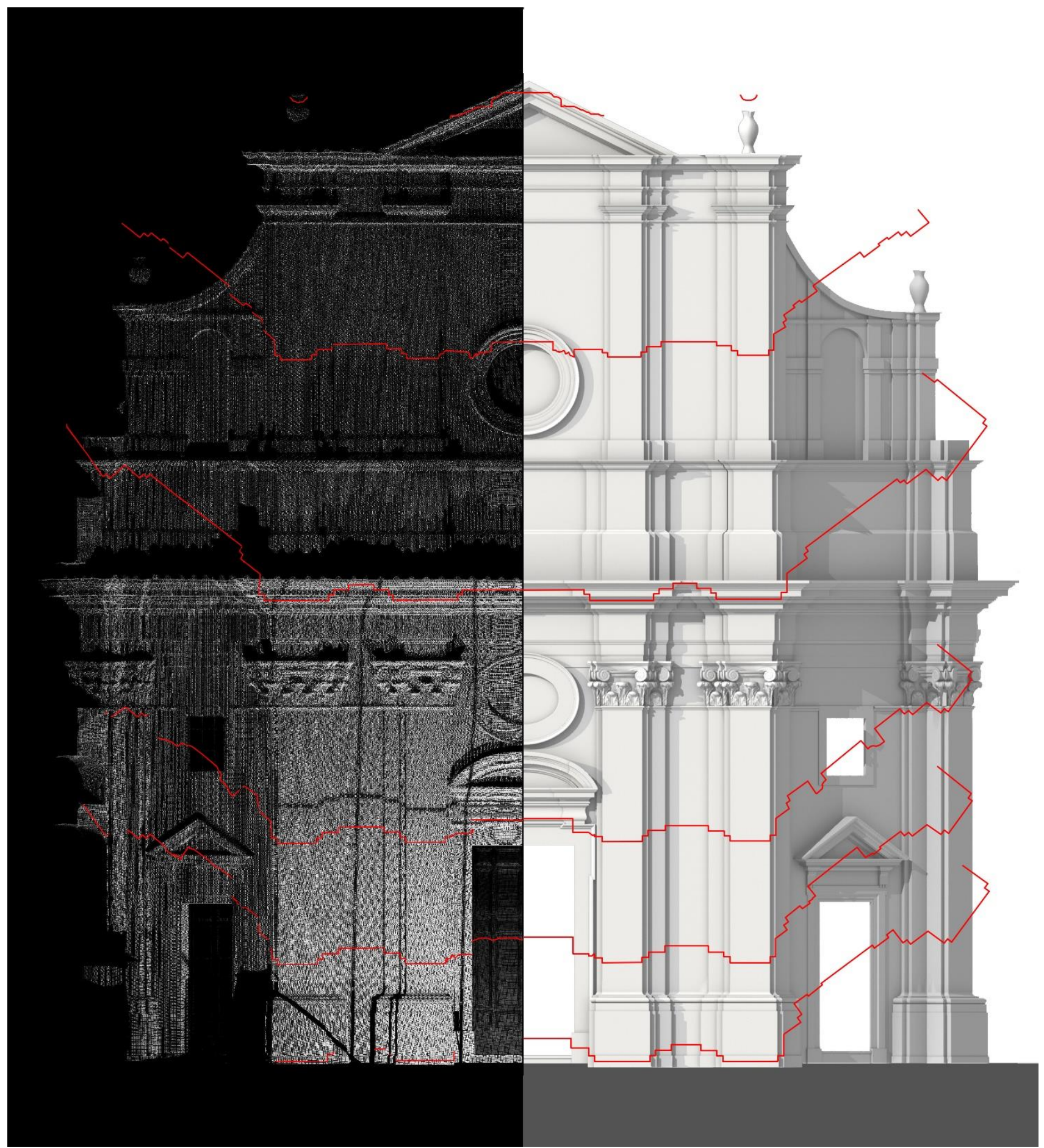

Figure 5. Visual comparison between the dense cloud (on the left) and the mathematical model (on the right) with the horizontal sections of the façade of the church of Maria SS. Assunta in Cielo

survey was considered insufficient to describe the complexity of the element; in addition, since the acanthus leaves are freeform surfaces that is not describable mathematically. Both polygonal model and ortho-image (Fig. 6) were useful for the construction of the mathematical model in Rhinoceros. The ionic portion of the capital (abacus, echino, volutes) was modelled through the integration of the information of the following data: ortho-image extracted from the textured polygonal model; sections obtained from the polygonal model; historical and geometrical study on architectural elements. The methodology was the same used for the construction of the whole façade, because these elements are composed of surfaces described mathematically. The model of the ionic part is composed of translation surfaces, identifying the direction lines (abacus and echino circumferences) and the generating lines (abacus and echino profiles). In particular, the volutes was constructed using the following steps: twodimensional drawing of the ionic volute according to the Vitruvio and Vignola procedures; introducing 30 degrees sloped volutes and superimposing them on the ortho-image, verifying its congruence; determination of the direction lines and generators. 
The Corinthian part (double turn of acanthus leaves) was modelled following a double procedure, since the acanthus leaves are the only freeform surfaces of the entire facade, therefore they cannot be described through mathematical formulas. The first procedure consists in the use of slanting curves, controlled through interpolation points, built exclusively by resting on the vertices of the mesh obtained from the structure from motion process, creating a network of curves on which the interpolation surface has been created. The second provides for the definition of some fundamental lines for the description of the shape, realized through skewed curves for interpolation of points on the mesh, subdivided by a number of points in order to build a second class of curves. In this case, the points no longer belonging to the vertices of the mesh, but the result of interpolation with the curves established a priori as fundamental curves for the definition of the shape (Fig. 7). This latter process has allowed to define a better controlled and suitable model. Besides, the first one has generated more adherent surfaces, especially in the overall view, although they present a more disordered and random geometry. The two methods (Fig. 8) seem to be both effective, although for different purposes: the first for a scale of detail, the second for an architectural scale.

\section{DATA ANALYSIS AND CONCLUSION}

The final 3D reconstructed model has been compared in Cloud Compare software with the starting 3D point cloud obtained by the survey campaign, in order to verify the global distance
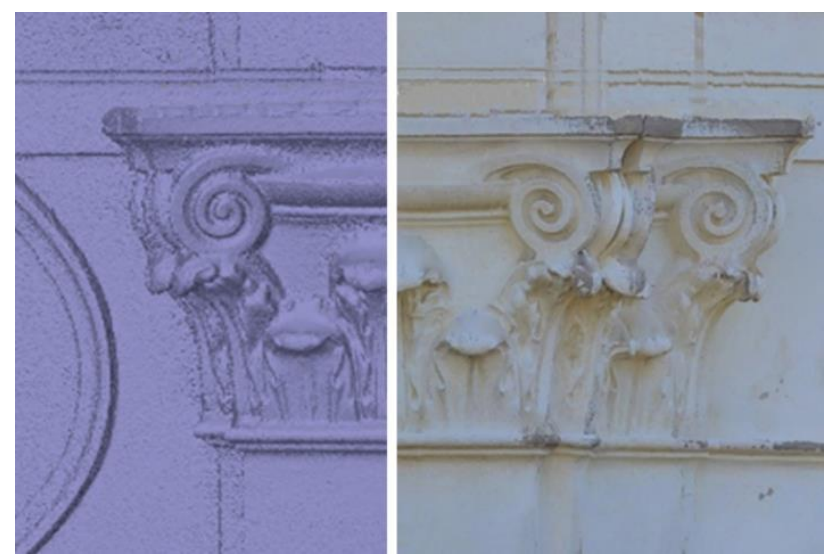

Figure 6. Polygonal model (left) and orthophoto (right) of the composite capital obtained with Structure from Motion process with Agisoft software

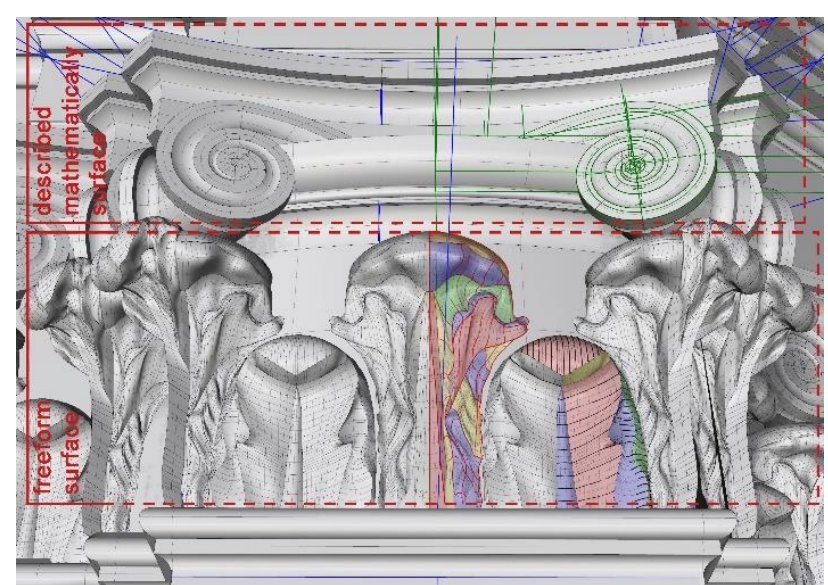

Figure 7. Construction of the surfaces of the Ionic and Corinthian parts of the capital with the different approaches and methods. between these two models, expanding the section comparison to the whole façade. The average error resulting from the comparison map (Fig. 9) is lower than $5 \mathrm{~cm}$, clearly within the predefined reconstruction tolerance, so the final suggested 3D model reach the double aim to preserve the final shape simplifying the real object.

From this comparison, however, it emerges that the façade is symmetrical; this confirms the hypothesis formulated initially. Moreover, as was reliable, the error increases with the high, this because of the overhang out of the interpretation, but also due to the lack of information due to the criticality of the survey.

The main errors are referred to the architectonic elements which were not modelled, such as fixtures and the connection with Palazzo Camuccini. The error in the areas of the capitals has not been considered significant because the capital has not been modeled through this cloud of point.

The present work focuses on a double level of discussion: on the one hand, it is a contribution to the debate on the whole process of $\mathrm{RM}$ applied to $\mathrm{CH}$ in architecture field, starting from the acquisition of the metric data up to the reconstruction of a real architectural object through a mathematical model; on the other, it investigates the possible uses of the model.

The RM of architecture presents several critical steps that should be foreseen in advance. The acquisition phase, despite benefiting from different methodologies and tools, can present problems due to the size of the architectural object, the behaviour of the materials with respect to the instruments used and the context in which it is inserted. Starting from acquired 3D data, the reading and interpretation phase is necessary, following geometric

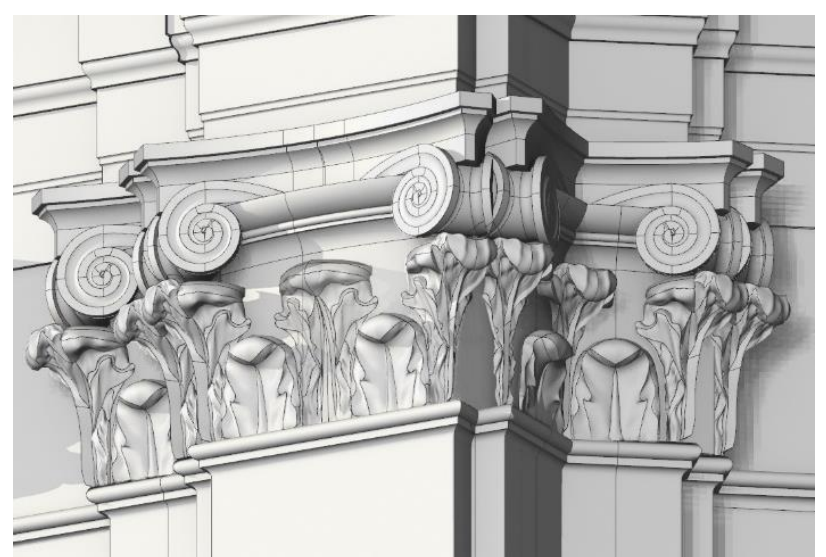

Figure 8. Mathematical model of the angular composite capital.

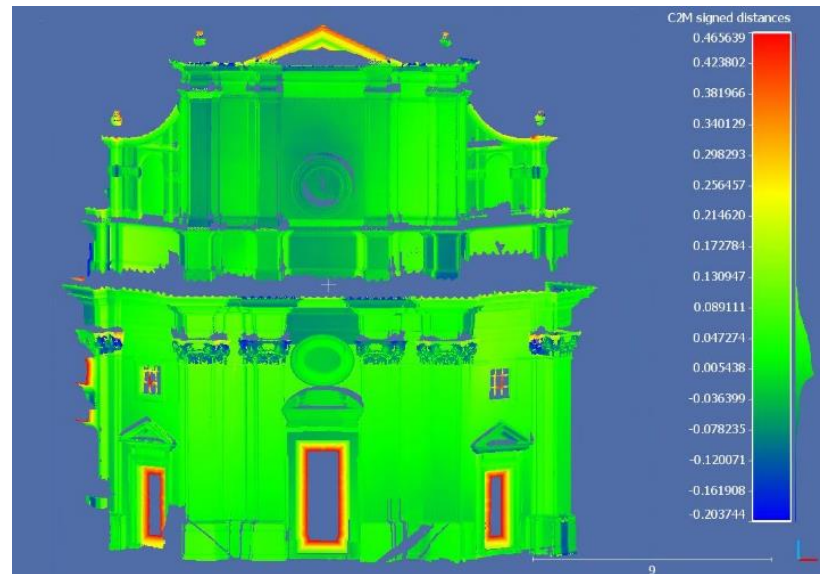

Figure 9. Result of the comparison between point cloud and mathematical model 


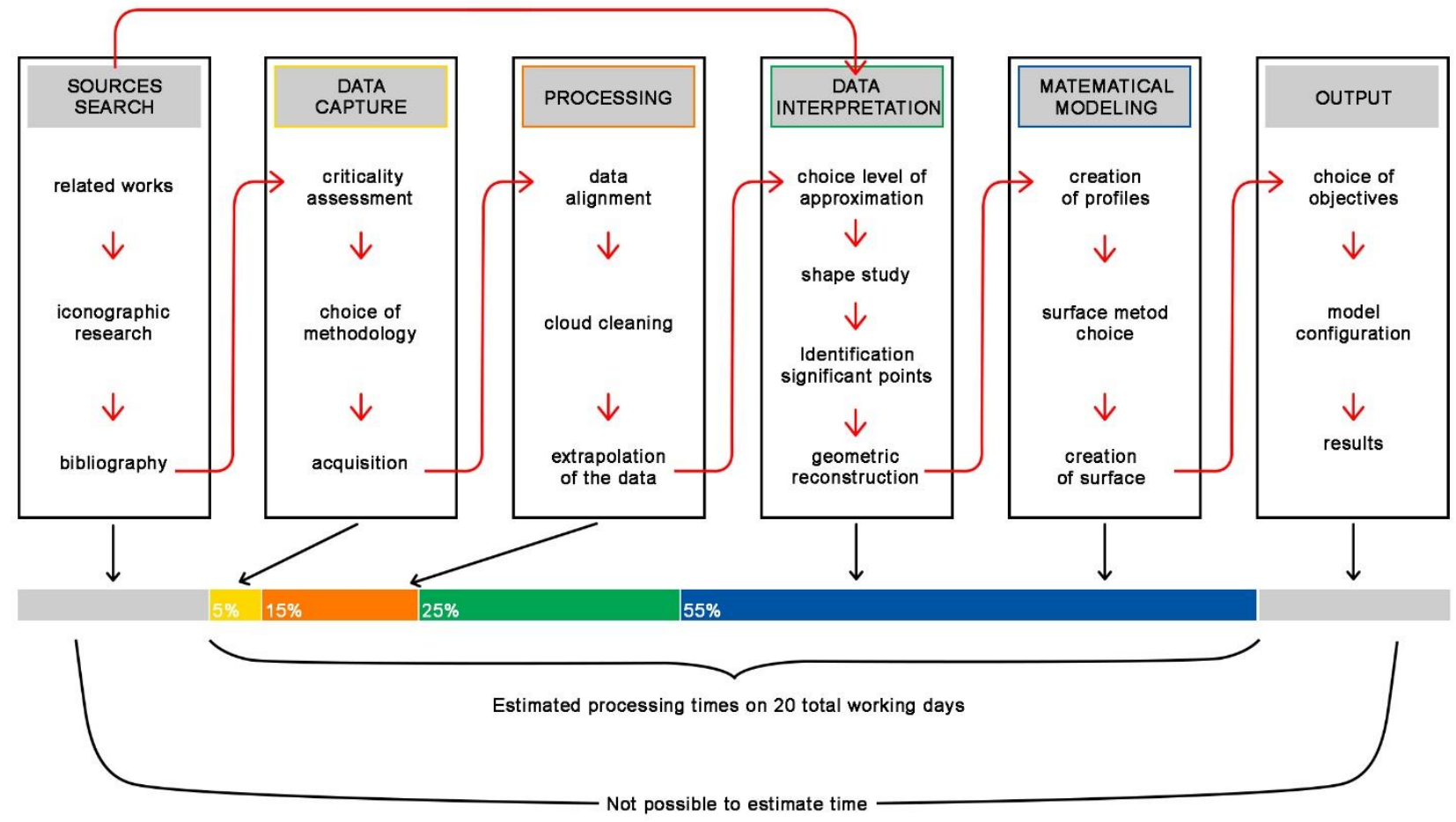

Figure 10. Pipeline of the Reverse Modeling process applied to Cultural Heritage

composition rules codified in the architectural treatises, in order to obtain a final reconstruction model as the best possible solution between the preservation of acquired $3 \mathrm{D}$ data and his interpretation. To obtain this result, a reconstruction tolerance

\section{Sketchfab EXPLORE}

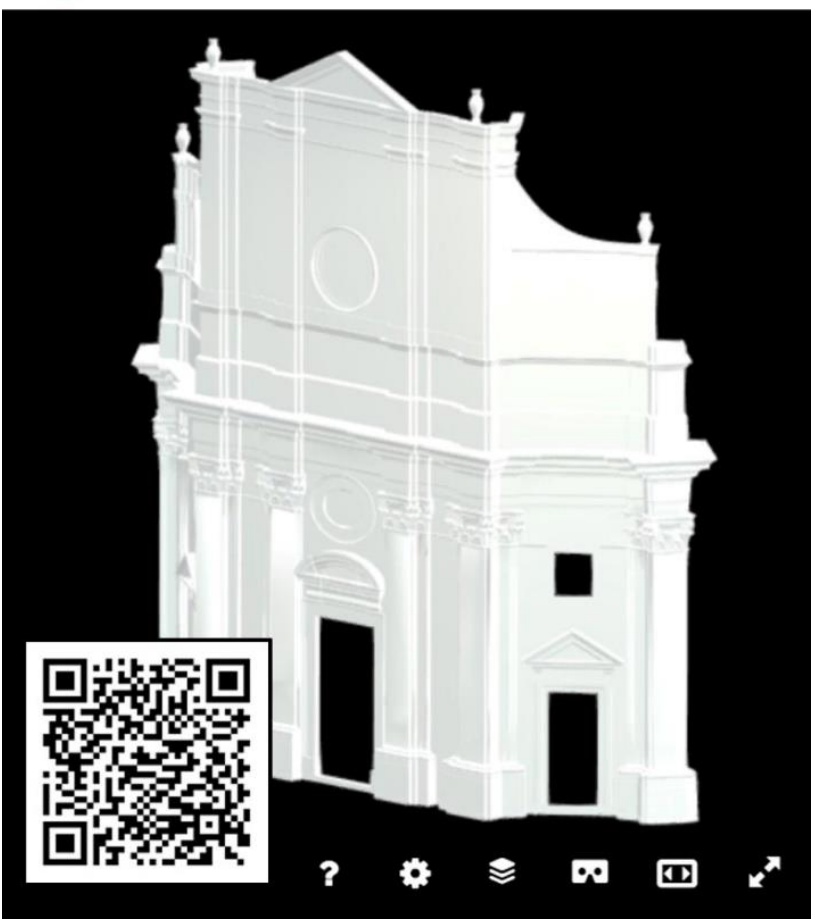

Figure 11. Example of using the model converted into a navigable mesh model on the Sketchfab platform should be considered in advance, defining a break-line between geometrical simplification and as-built restitution. This parameter is strictly referred to the final goal of the digital model, defining the reconstruction methodology, the final accuracy and reliability of the mathematical model. Although a mathematical model is suitable for many purposes, its creation requires a great effort of time and energy (Fig. 10). In fact, considering the process from survey to the finished model, the time allocated to the critical data interpretation and modeling is greater than that used for the acquisition and data processing. For this reason, is necessary to define the modeling purpose, otherwise it is not possible to estimate unequivocally the global time in advance. A digital mathematical model allows to obtain different outputs, as geometrical simulations and comparison or 3D visualization for communication and interaction purposes, defining a useful document of $\mathrm{CH}$ in many occasions.

Considering the semantic model structure, it can allow morphological or structural targeted analyses, assigning additional information to each architectural element, obtaining a 3D database. At last the final model is useful for dissemination and communication purposes, accessing to different multimedia contents through online navigable model in shared platforms. To insert the mathematical model in shared platforms it is necessary to convert the NURBS surface in mesh. (fig. 11). The mathematical model works as a "matrix" and can lend itself to different uses according to different needs. The mathematical model also allows, after having determined the various construction profiles, to make variations bringing the ideal model closer to the real one. In this way, one can compare the various models and formulate different evaluations thanks to their realtime comparison. For all these reasons, the final reconstructed model requires a global control of all the RM pipeline, anticipating possible bottlenecks and facing each passage with a flexible but clear methodology, supported by human interpretation and knowledge. 


\section{REFERENCES}

Apollonio, F.I., Gaiani, M., Sun, Z., 2013. 3d modeling and data enrichment in digital reconstruction of architectural heritage. In: International Archives of the Photogrammetry, Remote Sensing and Spatial Information Sciences, Vol. XL-5/W2, 2013, pp. 4348. https://doi.org/10.5194/isprsarchives-XL-5-W2-43-2013.

Benedetti, B., Gaiani M., Remondino F. 2010. Modelli digitali $3 d$ in archeologia: il caso di Pompei. Pisa: Edizioni della Normale, ISBN 9788876423536.

Bernardini, F., Rushmeier, H., 2002. The 3D Model Acquisition Pipeline. Computer Graphics Forum. New Jersey: WileyBlackwell Publishing, 21 (2), pp. 149-172. ISSN: 1467-8659.

Brusaporci, S., Centofanti, M., Continenza, R., Trizio, I., 2012. Sistemi Informativi Architettonici per la gestione, tutela e fruizione dell'edilizia storica. In: Atti 16a Conferenza Nazionale ASITA, pp. 315-322, ISBN 978-88-903132-7-1.

Brusaporci, S., 2012. Modelli 3D per il progetto di restauro. Il palazzo di Margherita d'Austria all'Aquila. Il disegno delle trasformazioni. Giornata di studi, Napoli

Buonamici, F., Carfagni, M., Furferi, R., Governi, L., Lapini, A., Volpe, Y., 2017. Reverse engineering modeling methods and tools: a survey. Computer-Aided Design and Applications. DOI: 10.1080/16864360.2017.1397894.

Clini, P., El Mehtedi, M., Nespeca, R., Ruggeri, L., Raffaelli, E., 2017. A digital reconstruction procedure from laser scanner survey to 3d printing: the theoretical model of the arch of Trajan (Ancona). In: SCIRES-IT SCIentific RESearch and Information Technology, Vol 7, Issue 2, pp. 1-12, DOI $10.2423 / \mathrm{i} 22394303 \mathrm{v} 7 \mathrm{n} 2 \mathrm{p} 1$

Di Carlo, E.A., 1989. Il castello di Cantalupo in Sabina. Tipografia Di Marcotullio.

Fallavollita, F., Ballabeni, M., Foschi, R., Perugini, G., 2015. Semantic description of three-dimensional models of Bologna porches. In: SCIRES-IT SCIentific RESearch and Information Technology, Vol 5, Issue 1, pp. 31-40, DOI $10.2423 / \mathrm{i} 22394303 \mathrm{v} 5 \mathrm{n} 1 \mathrm{p} 31$
Gaiani, M., Gamberini, E., Tonelli G., 2007. Realtà virtuale come strumento di lavoro per il restauro architettonico e archeologico: il 3D Virtual GIS "La Via Appia antica". In: Coralini Daniela, Scagliarini Corlàita (a cura di) UT NATURA ARS. Virtual Reality e archeologia. Atti della Giornata di Studi. University Press Bologna Imola, pp. 107-113.

Gaiani, M., Benedetti, B., Apollonio, F.I., 2011. Teorie per rappresentare e comunicare i siti archeologici attraverso modelli critici. In: SCIRES-IT SCIentific RESearch and Information Technology, Vol 1, Issue 2, pp. 33-70, DOI 10.2423/i22394303v1n2p33.

Gaiani, M., 2012. Creare Sistemi informativi per studiare, conservare, gestire e comunicare sistemi architettonici e archeologici complessi. In: Disegnarecon. Vol. 5, n. 10, Numero Speciale, DOI: 10.6092/issn.1828-5961/3277.

Guidi, G., Russo M., Angheleddu, D., 2014. 3D Survey and virtual reconstruction of archaeological sites. In: Digital Applications in Archaeology and Cultural Heritage. Elsevier, Amsterdam, 1, pp. 55-69. ISSN: 2212-0548.

Levoy, M., Pulli, K., Curless, B., Rusinkiewicz, S., Koller, D., Pereira, L., Ginzton, M., Anderson, S., Davis, J., Ginsberg, J., Shade, J., Fulk, D., 2000. The Digital Michelangelo Project: 3D scanning of large statues. In Proceedings of ACM SIGGRAPH. New York: SIGGRAPH, 2000, pp. 131-144.

Motavalli, S., 1998. Review of reverse engineering approaches. Computers \& Industrial Engineering, Vol. 35, pp.25-28. https://doi.org/10.1016/S0360-8352(98)00011-4.

Remondino, F., El-Hakim, S., 2006. Image-based 3d modelling: a review. The Photogrammetric Record, 21(115), pp. 269-291. https://doi.org/10.1111/j.1477-9730.2006.00383.x.

Várady, T., Martin, R.R., Cox, J., 1997. Reverse engineering of geometric models-an introduction. In: Computer-Aided Design, Vol. 29, pp. 255-268, https://doi.org/10.1016/S00104485(96)00054-1 .

Russo, M., Guidi G., 2011. Reality-based and reconstructive models: digital media for cultural heritage valorization. In: SCIRES-IT SCIentific RESearch and Information Technology, Vol. 2 (4), pp. 71-86. e-ISSN 2239-43 